\title{
Mono-Therapy versus Poly-Therapy: Ten Years Indian Experience on Various Seizure Disorders
}

\author{
Deepak Goel, Manish Mittal \\ Department of General Medicine, Swami Ram Himalayan University, Dehradun, India \\ Email: goeld007in@yahoo.co.in
}

Received 12 October 2015; accepted 9 November 2015; published 13 November 2015

Copyright (C) 2015 by author and Scientific Research Publishing Inc.

This work is licensed under the Creative Commons Attribution International License (CC BY). http://creativecommons.org/licenses/by/4.0/

\section{(c) (i) Open Access}

\begin{abstract}
Objectives: To find out prescription patterns and seizure freedom with different mono-, duo- and poly-therapies used in various seizure disorders in Indian setting. Material and Methods: Subjects with seizures, not responding to first antiepileptic drug, were evaluated prospectively for a period of 6 months. Patients on various dual antiepileptic drugs (AEDs) prescriptions were prospectively analyzed for 1) the pattern and frequency of different duo-therapies; 2) etiological profile of patients in duo-therapy prescription; and 3) frequency of seizure freedom on various duo-therapy groups. Results: Among 2542 patients, 293 (11.5\%) lost in follow-up and thus, 2249 (88.5\%) were followed. $1324(58.9 \%)$ had seizure freedom on mono-therapy, $532(23.7 \%)$ required duo-therapy and only $45(2 \%)$ were better controlled on poly-therapy. Among the subjects, who were on mono-therapy, Carbamazepine/0xcarbazepine was the most commonly prescribed in $1285(50.55 \%)$ patients as first drug followed by Valproate compound and Phenytoin. The most common duo- therapy used was combination of Valproate with Lamotregine, followed by Phenytoin and Phenobarbitone. Other mono-therapy and combinations are given in this paper. Conclusions: Duo-therapy was required and found to be effective in $23.7 \%$ of Indian patients with epilepsy. Selection of appropriate two drug combination is based on individual approach and overall clinical profile of patient.
\end{abstract}

\section{Keywords}

Antiepileptic Drugs, Refractory Epilepsy, Rationale Poly-Therapy

\section{Introduction}

Epilepsy is defined as a chronic, neurological condition whose cardinal feature is a predisposition to recurrent, unprovoked seizures. According to prevalence rate around 6 - 7 million persons in India are suffering from this 
disease [1]. The optimal goal of the therapy for patient with epilepsy is complete freedom from seizures on a single anti-epileptic drug (AED) which is affordable to the patient and does not have any adverse effect. Available evidences also recommend AED mono-therapy as the initial step for new onset epilepsy cases [2] [3]. Medical treatment statistics also suggest that around 50\% patients can have seizures freedom from mono-therapy [4]. However, the rest of the halves do not achieve complete remission even with maximally tolerated dosage of single AED [5] [6]. The failure of mono-therapy has evolved the concept of combining two or more AEDs (polytherapy) for better control of seizures [7]. Poly-therapy is associated with a number of problems, e.g., high cost, higher rates of drug toxicity and unwanted drug interactions; therefore it is prescribed only when first drug fails [8]. The selection of first drug and types of drug combinations is largely based on clinician's choice, experiences and available guidelines.

Second issue for clinicians in treatment of patient with epilepsy in India is selection of conventional drugs versus newer drugs. Evidences suggest that there is no major difference in efficacy of conventional versus newer AEDs. However, newer drugs are better tolerated and have lesser interactions with other drugs but make the therapy costlier. We have been more commonly using conventional AEDs as the first line therapy for our patients over more than 10 years due to low-middle socio-economic status of our patients and no wide availability of new drugs in rural area. Here, we are presenting our experience regarding prescription pattern and response of various mono- and poly-therapies. This paper can be of help to the general physicians who are treating poor patients and will give them an idea regarding appropriate selection and mixing of AEDs.

\section{Methods}

Our data collection started in year 2001 up to 2010, after obtaining approval from institutional ethics committee. The rationale of the study was explained to the patients included in this study and informed consent was taken.

Consecutive patients of epilepsy presenting to the neurology clinic were diagnosed and classified according to ILAE classification 1989. Etiologically, cases were classified into two groups a) acute symptomatic with ring lesion (s), b) Epilepsies and Epileptic syndromes. The latter category, i.e., "epilepsies and epileptic syndromes" were further sub-classified according to ILAE classification 1989 and three categories were made; 1) idiopathic epilepsies (ILAE category 1.1 and 2.1); 2) symptomatic/cryptogenic partial epilepsies (category 1.2 and 1.3); and 3) cryptogenic/symptomatic generalized and undetermined epilepsies (ILAE categories 2.2, 2.3 and 3). However, cases of category 4.1 (situation related seizures) were not included. Thus, we had four groups of epilepsy: group I: acute symptomatic seizures; group II: idiopathic epilepsies; group III: symptomatic/ cryptogenic partial seizures and lastly, group IV: cryptogenic/symptomatic generalized and undetermined epilepsies. Patients in each of these groups were either new onset or follow-up case. We have developed a protocol at our center to prescribe various AEDs in a step wise pattern (vide infra). The aim of the treatment was to get complete freedom from disabling seizures. It was defined as no occurrence of seizures with regular usage of medicine and was documented on each monthly follow-up. Steps given below were followed for selection of antiepileptic drugs in various etiological groups.

Step 1 (first drug): Patients having acute symptomatic seizures (group I), symptomatic/cryptogenic partial (group III) were initially prescribed either phenytoin sodium (PHT) or Oxcarbazepine/carbamazipine (OXC/ CBZ) as a first AED. On the other hand, patients with idiopathic epilepsies (group II) were prescribed valproate compounds (VAL) or phenobarbitone (PB), lamotrigine (LTG) or Levetiracitam (LEV) as a first medicine depending on age, sex and affordability. In cryptogenic/symptomatic generalized and undetermined epilepsies (group IV) this is heterogeneous group and first drug selection was mainly based on seizure types and patient's characteristics (can be CBZ/OXC, PB, PHT, VPA or newer AED). Patient with West syndrome was additionally given ACTH/steroids with antiepileptic medicine.

Step 2: Those who had persistent seizures on first drug were given add-on drug and those who had not tolerated the drugs were given alternative mono-therapy. Add-on drug was clobazam, phenobarbitone, sodium valproate or newer drugs in groups I \& III. Lamotrigine, clonazepam, levetiracetam were added in group II and any old or other newer antiepileptics were added in group IV depending on primary diagnosis, seizure type (s) and first drug given. The selection of first and additional AED was dependent on patients profile, affordability and local availability to patient's home.

These patients were followed for maximum possible period and analysis was done in year 2014 to find out the 1) prescription pattern of various mono and poly therapies in various etiologies and 2) rate of complete seizure freedom on various mono- and poly-therapies in new onset and old cases of various epilepsy. 


\section{Results}

A total of 2542 patients were included in this study (Table 1). Among these, 1119 (44\%) were new onset while 1423 (56\%) were old follow-up cases registered due to either poor control of relapse after discontinuing drug.

Etiologically, acute symptomatic seizures due to ring lesion(s) were found in $684(26.9 \%)$ patients (569 new + 115 old), idiopathic epilepsies in 562 (22.1\%) (219 new + 343 old), symptomatic/cryptogenic partial epilepsies in 722 (28.4\%) (177 new +545 old) and cryptogenic/symptomatic generalized or undetermined in 574 (22.6\%) (158 new +416 old) (Table 1$)$.

Patterns of various mono-therapy and poly-therapies: All 2542 patients were analyzed for the assessment of prescription patterns of antiepileptic medicines.

Group I: Total 684 (26.9\%) patients were enrolled in this group. Total 60 patients lost in follow-up and 624 were further followed-up. Among these 475 (76.1\%) were given CBZ/OXC and 209 (33.5\%) given PHT as first drug. Total 61 (9.8\%) patients were given alternative Mono-therapy (VPA/PB/CLOB/LEV) due to drug allergy and poor tolerance to first drug. Total 515 (82.5\%) had freedom on first drug selected remaining 109 (17.5\%) required add-on drugs for ongoing seizures. Further 81 (13\%) patients had seizure freedom on duo-therapy and only 7 (1.1\%) patients remitted on more than 2 drugs. Twenty one (3.4\%) patients were poorly controlled even after poly-therapy. Most common combinations were PHT+PB (48 patients) and CBZ/OXC + CLOB (24 patients).

Group II: Total 562 (22.1\%) patients were enrolled. Total 489 (87\%) were given valproate compound and 73 (13\%) other types of Monotherapy as first drug (PB, LTG, LEV or CZP). After first prescription 73 (13\%) patients lost in follow-up and 489 (87\%) were followed, among which 253 (51.7\%) were seizure free on monotherapy, 164 (33.5\%) on duo therapy and 19 (3.9\%) on poly-therapy. Twenty one (4.3\%) patients were given alternative mono-therapy due poor tolerance or side effects to first drug. Fifty three (10.8\%) patients were having poor seizures control. Most common combination was VPA+LTG (146 patients) followed by VPA + CZP (58 patients) in this group.

Group III: Total 722 (28.4\%) patients in this group were either given CBZ/OXC (in 544 (75.3\%) patients) or PHT (in 178 (24.7\%) patients). Then 83 (11.5\%) were lost in follow-up and finally 639 (88.5\%) patients were followed. During follow-up 342 (53.5\%) had freedom on single drug, 160 (25\%) on duo-therapy and 6 (0.9\%) on poly-therapy, rest 131 (20.5\%) used to have break-through seizures even on poly-therapy. Total 66 (10.3\%) patients were given alternative mono-therapy due to side effects by first drug.

Group IV: This was the most heterogeneous group of 574 (22.6\%) patients and CBZ/OXC was most commonly used (in 266 (46.3\%) patients) then VPA (in 242 (42.1\%) patients) and PHT (in 66 (11.5\%) patients). After losing 77 (13.4\%) patients in follow-up, 214 (43\%) had seizure freedom on single drug, 127 (25.6\%) on duo-therapy and 12 (2.4\%) on poly therapy. Total 144 (29\%) continued to have poor controlled. VAL + LTG (in 63 patients), CBZ/OXC + CLOB (in 52 patients), OXC/CBZ + PB or VPA (in 38 patients each) and PHT + PB (in 30 patients) were most common duo-therapies.

\section{Table 1. General parameters.}

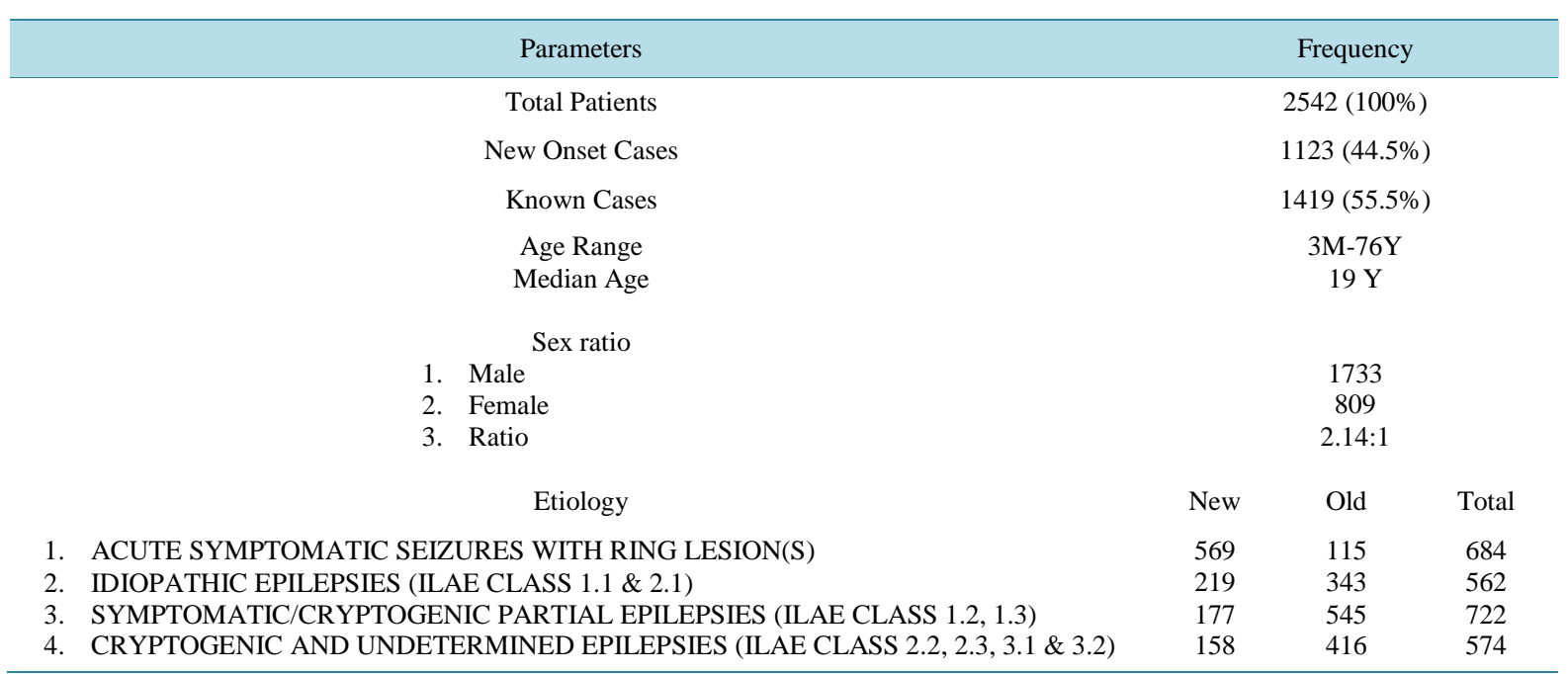




\section{Seizure Freedom in New versus Old Cases}

New onset seizures (Table 2): Out of 1123 (44.2\%) patients in new onset seizures, 114 patients were lost in follow-up, rest 1009 (89.8\%) had mean follow-up of 19 months (3 - 84 months). Total 799 (79.1\%) patients had seizure freedom after first drug, $154(15.2 \%)$ on duo-therapy and $8(0.8 \%)$ on poly-therapy.

Follow up cases (Table 3): Total 1419 (55.8\%) patients were already known cases of recurrent seizures presented either due to relapse after stopping AED (288 patients) or due to drug refractory seizures (1131 patients). All 288 Patients who presented after relapses were re-started antiepileptic drug and 235 (81.6\%) again had seizure freedom (163 on mono-therapy and 70 on duo-therapy).

Second sub group of 1131 (79.7\%) patients presented with poorly controlled seizures on drugs prescribed outside. On adequate doses of appropriate drug 362 (32\%) patients could achieve seizure freedom on monotherapy. Moreover, 308 (27.2\%) on two drugs and 34 (3\%) on more than 2 drugs were controlled, while 285 (25.2\%) still had poor control.

Frequency of various mono-therapy and duo-therapy (Table 4): Carbamazepine/Oxcarbazepine (CBZ/OXC) was the most commonly prescribed mono-therapy in 1285 (50.55\%) patients as first drug followed by VPA (in 731 patients) and PHT (in 453 patients). Most common Duo-therapy used was VPA+LTG (in 219 patients), followed by PHT + PB (164 patients), CBZ/OXC + CLB (in 150 patients), CBZ/OXC+PB (in 130 patients), $\mathrm{CBZ/OXC}+\mathrm{VPA}$ (in 80 patients), and VPA+CZP (in 65 patients). Otherwise more than 60 different combinations of poly-therapy were used. Total 208 (8.18\%) patients were given alternative mono-therapy due to side effects with first agent.

Overall freedom (Table 5): Among 2542 patients, 293 (11.5\%) lost in follow-up and 2249 (88.5\%) were followed. With treatment 1324 (58.9\%) had seizure freedom on mono-therapy, 532 (23.7\%) required duo-therapy and only 45 (2\%) were better controlled on poly-therapy.

Table 2. Outcome in new onset cases.

\begin{tabular}{ccccccc}
\hline Etiology & $\begin{array}{c}\text { New onset } \\
(\mathrm{n}=1123)\end{array}$ & $\begin{array}{c}\text { Seizure freedom } \\
\text { on single drug }\end{array}$ & $\begin{array}{c}\text { Seizure freedom } \\
\text { on two drugs }\end{array}$ & $\begin{array}{c}\text { Seizure freedom } \\
\text { on more than } \\
\text { two drugs }\end{array}$ & $\begin{array}{c}\text { Poor control } \\
\text { even after } \\
\text { poly-therapy }\end{array}$ & $\begin{array}{c}\text { Lost in } \\
\text { follow-up }\end{array}$ \\
\hline $\begin{array}{c}\text { Acute symptomatic } \\
\text { Seizures with ring lesions } \\
\begin{array}{c}\text { Symptomatic/cryptogenic } \\
\text { Partial epilepsies }\end{array}\end{array}$ & $569(50.7 \%)$ & $461(41 \%)$ & $50(4.5 \%)$ & $3(0.3 \%)$ & $7(0.6 \%)$ & $48(4.3 \%)$ \\
$\begin{array}{c}\text { Idiopathic epilepsies } \\
\begin{array}{c}\text { Cryptogenic/symptomatic } \\
\text { generalized or }\end{array}\end{array}$ & $177(15.8 \%)$ & $117(10.4 \%)$ & $29(2.6 \%)$ & $0(0 \%)$ & $13(1.2 \%)$ & $18(1.6 \%)$ \\
$\begin{array}{c}\text { Undetermined epilepsy } \\
\text { Total }\end{array}$ & $158(14 \%)$ & $90(8 \%)$ & $24(2.2 \%)$ & $1(0.1 \%)$ & $21(1.9 \%)$ & $22(2 \%)$ \\
\hline
\end{tabular}

Table 3. Outcome in old follow-up cases.

\begin{tabular}{|c|c|c|c|c|c|c|}
\hline Etiology & $\begin{array}{l}\text { Old cases } \\
(\mathrm{n}=1419)\end{array}$ & $\begin{array}{c}\text { Seizure } \\
\text { freedom } \\
\text { on single drug }\end{array}$ & $\begin{array}{c}\text { Seizure } \\
\text { freedom } \\
\text { on two drugs }\end{array}$ & $\begin{array}{c}\text { Seizure freedom on } \\
\text { more } \\
\text { than two drugs }\end{array}$ & $\begin{array}{l}\text { Poor control } \\
\text { even after } \\
\text { poly-therapy }\end{array}$ & $\begin{array}{l}\text { Lost in } \\
\text { follow-up }\end{array}$ \\
\hline $\begin{array}{l}\text { Acute symptomatic seizures } \\
\text { with ring lesion (s) }\end{array}$ & $115(8.1 \%)$ & $54(3.8 \%)$ & $31(2.2 \%)$ & $4(0.3 \%)$ & $14(1 \%)$ & $12(0.9 \%)$ \\
\hline $\begin{array}{l}\text { Symptomatic/cryptogenic } \\
\text { partial epilepsies }\end{array}$ & $343(24.2 \%)$ & $122(8.6 \%)$ & $113(8 \%)$ & 15 (1.05\%) & $46(3.2 \%)$ & $47(3.3 \%)$ \\
\hline Idiopathic epilepsies & $545(38.4 \%)$ & 225 (15.9\%) & $131(9.2 \%)$ & $6(0.4 \%)$ & $118(8.3 \%)$ & $65(4.6 \%)$ \\
\hline $\begin{array}{l}\text { Cryptogenic/symptomatic } \\
\text { generalized and } \\
\text { undetermined epilepsies }\end{array}$ & $416(29.3 \%)$ & $124(8.7 \%)$ & $103(7.3 \%)$ & $11(0.8 \%)$ & $123(8.7 \%)$ & $55(4 \%)$ \\
\hline Total & 1419 & 525 (37\%) & 378 (26.6\%) & 36 (2.5\%) & 301 (21.2\%) & 179 (12.6\%) \\
\hline
\end{tabular}


Table 4. List of drug used.

\begin{tabular}{|c|c|c|c|c|c|c|c|c|c|}
\hline Group & $\mathrm{CBZ/OXC}$ & PHT & VPA & $\begin{array}{c}\text { CBZ/OXC } \\
+ \\
\text { CLOB }\end{array}$ & $\begin{array}{c}\mathrm{CBZ} / \mathrm{OXC} \\
+ \\
\mathrm{PB}\end{array}$ & $\begin{array}{c}\mathrm{CBZ} / \mathrm{OXC} \\
+ \\
\mathrm{VPA}\end{array}$ & $\begin{array}{c}\text { PHT } \\
+ \\
\text { PB }\end{array}$ & $\begin{array}{l}\text { VPA } \\
+ \\
\text { LTG }\end{array}$ & $\begin{array}{c}\text { VPA } \\
+ \\
\text { CZP }\end{array}$ \\
\hline I & 475 & 209 & 0 & 24 & 13 & 4 & 48 & 0 & 0 \\
\hline II & 0 & 0 & 489 & 0 & 0 & 9 & 13 & 146 & 58 \\
\hline III & 544 & 178 & 0 & 74 & 79 & 29 & 73 & 10 & 0 \\
\hline IV & 266 & 66 & 242 & 52 & 38 & 38 & 30 & 63 & 7 \\
\hline Total & 1285 & 453 & 731 & 150 & 130 & 80 & 164 & 219 & 65 \\
\hline
\end{tabular}

Table 5. Final outcome in all patients.

\begin{tabular}{|c|c|c|c|c|c|c|c|}
\hline Group & Total patients & $\begin{array}{l}\text { Lost in } \\
\text { follow } \\
\text { up }\end{array}$ & Patients followed & $\begin{array}{l}\text { Seizure freedom } \\
\text { on } 1^{\text {st }} \text { AED }\end{array}$ & $\begin{array}{l}\text { Seizure freedom } \\
\text { on } 2^{\text {nd }} \text { AED }\end{array}$ & $\begin{array}{l}\text { Seizure freedom } \\
\text { on } 3^{\text {rd }} \text { AED }\end{array}$ & Combined \\
\hline I & 684 & 60 & 624 & 515 & 81 & 8 & 604 \\
\hline II & 562 & 73 & 489 & 253 & 164 & 19 & 436 \\
\hline III & 722 & 83 & 639 & 342 & 160 & 6 & 508 \\
\hline IV & 574 & 77 & 497 & 214 & 127 & 12 & 353 \\
\hline Total & 2542 & 293 (11.5\%) & 2249 (88.5\%) & 1324 (58.9\%) & 532 (23.7\%) & 45 (2\%) & 1901 (84.5\%) \\
\hline
\end{tabular}

\section{Discussion}

Findings of our study suggest that around 83\% patients achieved seizure freedom on treatment and 59\% had got the seizure freedom on mono-therapy. New onset epilepsy had better response to therapy as compared to followup cases. Significant numbers (23.7\%) required duo-therapy for seizure freedom. Carbamazepine or oxcarbazepine were the most common mono-therapy while valproate with lamotrigine was the most common duo-therapy used in our experience.

The goal of antiepileptic therapy is to achieve a seizure-free state and to improve the quality of life (QOL) [9]. The antiepileptic treatment that effectively prevents the occurrence of seizures, with minimum drug related side effects, provides the best QOL and ensures patient satisfaction [9]-[11]. Nearly 2/3 of our patients were controlled on single drug, while 1/3 required two or more than two drugs for effective seizure control. Results on freedom in our study are in concordance with other international studies. Elwes et al. had shown $79 \%$ freedom rate for 2 years [12]. Sillanpaa et al. and collaborative group had one year freedom rate of $80 \%$ and $70 \%$ respectively in new onset epilepsy [13] [14]. In Glasgow's study 47\% new onset epilepsy patients went into freedom with institution of first drug, $13 \%$ with second drug and only $4 \%$ with third drug [15]. Similarly in our study the freedom rate was $58.9 \%$ with first drug, $23.7 \%$ with second drug and only $2 \%$ with third drug. Total $83 \%$ patients in our study could attain seizure freedom. The higher rate of seizure freedom with first drug in our study can be due to inclusion of neurocysticercosis cases that present with acute symptomatic seizure and remit easily with mono-therapy until there is massive infestation of brain.

In order of frequency carbamazepine or oxcarbazepine, valproate compound and phenytoin sodium were the most commonly prescribed mono-therapy at our center and similarly reported by others [16]. Once maximum doses of first drug fails in controlling seizures, clinicians has two options either go for alternative mono-therapy or try add-on therapy. Which approach is better between the two is debatable and study suggestes both the approaches have almost similar chances of seizure freedom [17] [18]. Positive results in various clinical trials on add-on therapy and marked deterioration in seizure control on discontinuation of concomitant drug in patients with refractory epilepsy, argue in favor of poly-therapy. However, similar degree of benefit could have been achieved by substituting other mono-therapy rather than adding second drug in a follow-up study from Finland [19]. Therefore many centers prefer alternative mono-therapy before attempting poly-therapy in cases of first drug failure. At our center we preferred for adjuvant therapy rather alternative mono-therapy in first drug failure 
cases. Only about $8 \%$ patients who had adverse drug reaction to first AED were given alternative mono-therapy.

Nearly one quarter of our patients were prescribed duo-therapy to achieve seizure freedom. In Finland study also ultimately $15 \%$ patients required duo-therapy to control their seizures. Selection of appropriate combination of AED is as important as the selection of most appropriate mono-therapy. Rationale drug combinations are available in anti-cancer and anti-infection chemotherapy, to produce greater therapeutic benefits. However, combining two AEDs to get better therapeutic efficacy for patients having difficult to treat epilepsy, is still debatable. Long discussion is continued about the good and bad aspects of various combinations of antiepileptic medication. Few questions were discussed in literature like: is there a rationale for this practice? Is there any evidence that two drugs in combination may do better than one in selected individuals? Are some drug combinations preferable to other? [20].

The antiepileptic drug combination can be labeled as acceptable when the two agents interact to produce superior efficacy without a parallel rise in side effects. In principle, antiepileptic drugs with similar mode of action should not be combined together because the effect of combination could be achieved simply by increasing the dose of one of these drugs. Though our knowledge is grossly incomplete but available evidence suggests that phenobarbitone, benzodiazapines and valproate act through prolongation of inhibitory post-synaptic potentials (IPSP) by increasing the mean chloride channel opening time and duration of GABA induced burst of neuronal activity. Sodium valproate additionally acts by limiting sustained, repetitive neuronal firing through voltage dependent sodium channel. Phenytoin sodium, carbamazepine, oxcarbazepine and Lamotrigine primarily act through inhibiting voltage gated sodium channel. Thus we can presume that AED acting on sodium channel (PHT, CBZ, OXC \& LTG) can be effectively combined with either PB, CZP or VPA. In our study combinations of duo-therapies were selected on the same principle. In animal models it was also found that combining two drugs with different mode of action can produce better anticonvulsant effects than those produced by individual agent when given alone [21] [22]. In Finland study only 15\% patients with refractory epilepsy responded well to the combination of phenytoin and carbamzepine, which have similar mode of action. In other similar type study almost half of the patients, who were refractory to two sequential mono-therapies, were improved when two drugs with different mechanism of action were given together [23]. Singapore group found that a quarter of patients required two drug combination and the most common and effective combination prescribed was carbamazepine and valproate. In various other studies from different centers the percentage of poly- therapy used in epilepsy ranges from $12 \%$ - 37\% [16].

Various drug combinations used as duo-therapy in our study were selected on the basis of underlying etiology and predominant seizure type. In generalized epilepsy VPA + LTG, in partial epilepsy CBZ/OXC+PB, in unclassified epilepsy VPA + CBZ/OXC and for acute symptomatic seizures CBZ/OXC + CLB were the most frequent combinations. The study from Singapore has shown that the most common combination in their study was VAL+CBZ [16]. Combination of VPA+LTG has additional advantage of synergistic effect when used together and taken as single bed time dose schedule for better drug compliance thus it is useful in broad spectrum epileptic disorders [24]. The relative disadvantages are high cost and increased reported risk of cutaneous reaction with combination of VPA + LTG [25]. Five percent of our patients had allergic reaction and required discontinuation of LTG. Extended release preparations of divalproex sodium made it easier to give once a day dosing schedule and can be effectively combined with clonazepam and lamotrigine for patients of primary generalized epilepsy [26] [27].

Clobazam, as suggested, was mainly used as add-on antiepileptic for short duration in acute symptomatic seizures cases like neurocysticercosis [28]. Ultimately many patients in this group were controlled on mono-therapy as clobazam was tapered off.

A fixed dose formulation combination of phenobarbitone with phenytoin is available in Indian market for many years. This combination is found to be associated with good potency with no increment in neuron-toxicity [29] [30]. This is the cheapest combination and is useful for large population of symptomatic and cryptogenic epilepsy associated with generalized tonic-clinic seizures. Combining phenobarbitone with carbamazepine was also found to be effective co-medication [31]. Although there are chances of increase CBZ metabolism (thus reducing drug level) due to hepatic enzyme inducing effect of $\mathrm{PB}$, but we have not experienced any negative clinical effect of this interaction.

Antiepileptic with shorter half life requires 2 - 3 daily doses and frequently results in breakthrough seizures even when single day dose is missed by patients [32]. One additional advantage of addition of PB to PHT or CBZ and CZP or LTG to VPA is prolongation in half life of the combined formulation. This leads to lesser 
chances of breakthrough seizures. Though, this should not be taken as an indication of duo-therapy.

Apparent disadvantage of combining drugs with same mode of action is additive neurotoxic side effects of antiepileptics. The combinations used in our study had not shown any such effects in short term follow-up. Phenobarbitone is a poor add-on drug with valproate due to more neurotoxic effect through GABAergic neurons [33]. Combination of carbamazepine and phenytoin was never used at our center due to its bad pharmacokinetic interaction and increase in neurotoxicity [34] [35].

Our study is important as scanty data is available on the impact of duo-therapy in epilepsy management of Indian patients. Since a significant proportion of epileptic patients in hospital setting need duo-therapy, this study can help in selection of appropriate combination.

\section{References}

[1] Sridharan, R. and Murthy, B.N. (1999) Prevalence and Pattern of Epilepsy in India. Epilepsia, 40, 631-636. http://dx.doi.org/10.1111/j.1528-1157.1999.tb05566.x

[2] Beghi, E. and Perucca, E. (1995) The Management of Epilepsy in the 1990s: Acquisitions, Uncertainties and Priorities for Future Research. Drugs, 49, 680-694. http://dx.doi.org/10.2165/00003495-199549050-00004

[3] Perucca, E. (1996) Established Antiepileptic Drugs. Baillieres clin Neurol, 5, 693-722.

[4] Beghi, E., Di Mascio, R. and Tognoni, G. (1986) Drug Treatment of Epilepsy: Outlines, Criticism and Perspectives. Drugs, 31, 249-265. http://dx.doi.org/10.2165/00003495-198631030-00003

[5] Schmidt, D. (1982) Two Antiepileptic Drugs for Intractable Epilepsy with Complex-Partial Seizures. Journal of Neurology, Neurosurgery \& Psychiatry, 45, 1119-1124. http://dx.doi.org/10.1136/jnnp.45.12.1119

[6] Brodie, M.J. and Mumford, J.P. (1999) Double-Blind Substitution of Vigabatrin and Valproate in Carbamazepine-Resistant Partial Epilepsy. Epilepsy Research, 34, 199-205. http://dx.doi.org/10.1016/S0920-1211(98)00110-7

[7] Reynolds, E.H. and Shorvon, S.D. (1981) Monotherapy or Polytherapy for Epilepsy? Epilepsia, 22, 1-10. http://dx.doi.org/10.1111/j.1528-1157.1981.tb04327.x

[8] Reynolds, E.H. and Shorvon, S.D. (1981) Single Drug or Combination Therapy for Epilepsy? Drugs, 21, 474-482. http://dx.doi.org/10.2165/00003495-198121050-00005

[9] Birbeck, G.L., Hays, R.D., Cui, X.P. and Vickrey, B.G. (2002) Seizure Reduction and Quality of Life Improvements in People with Epilepsy. Epilepsia, 43, 535-538. http://dx.doi.org/10.1046/j.1528-1157.2002.32201.x

[10] Collings, J.A. (1990) Epilepsy and Well Being. Social Science \& Medicine, 31, 165-170. http://dx.doi.org/10.1016/0277-9536(90)90058-Z

[11] Leidy, N.K., Elixhauser, A., Vickrey, B., Means, E. and William, M.K. (1999) Seizure Frequency and Health Related Quality of Life of Adults with Epilepsy. Neurology, 53, 162-166. http://dx.doi.org/10.1212/WNL.53.1.162

[12] Elwes, R.D., Johnson, A.L., Shorvon, S.D., et al. (1984) The Prognosis for Seizure Control in Newly Diagnosed Epilepsy. The New England Journal of Medicine, 311, 944-947. http://dx.doi.org/10.1056/NEJM198410113111503

[13] Sillanpaa, M., Jalava, M., Kaleva, O., et al. (1998) Long-Term Prognosis of Seizures with Onset in Childhood. The New England Journal of Medicine, 338, 1715-1722. http://dx.doi.org/10.1056/NEJM199806113382402

[14] Collaborative Group for the Study of Epilepsy (1992) Prognosis of Epilepsy in Newly Referred Patients: A Multicenter Prospective Study of the Effects of Monotherapy on the Long-Term Course of Epilepsy. Epilepsia, 33, 45-51. http://dx.doi.org/10.1111/j.1528-1157.1992.tb02281.x

[15] Kwan, P. and Brodie, M.J. (2001) Effectiveness of First Antiepileptic Drug. Epilepsia, 42, 1255-1260. http://dx.doi.org/10.1046/j.1528-1157.2001.04501.x

[16] Lim, S.H., Tan, E.K. and Chen, C. (1997) Pattern of Anti-Epileptic Drug Usage in a Tertiary Referral Hospital in Singapore. Neurological Journal of South East Asia, 2, 77-85.

[17] Kwan, P. and Brodie, M.J. (2000) Epilepsy after First Drug Fails: Substitution or Add-On? Seizure, 9, 464-468. http://dx.doi.org/10.1053/seiz.2000.0442

[18] Stephen, L.J. and Brodie, M.J. (2012) Antiepileptic Drugs Monotherapy versus Polytherapy: Pursuing Seizure Freedom and Tolerability in Adults. Current Opinion in Neurology, 25, 164-172. http://dx.doi.org/10.1097/WCO.0b013e328350ba68

[19] Shorvon, S.D. and Reynolds, E.H. (1979) Reduction in Polytherapy for Epilepsy. BMJ, 2, 1023-1025. http://dx.doi.org/10.1136/bmj.2.6197.1023

[20] Brodie, M.J. and Graeme, J.S. (2011) Combining Antiepileptic Drugs—Rationale Polytherapy? Seizure, 20, 369-375. http://dx.doi.org/10.1016/j.seizure.2011.01.004 
[21] Hakkarainen, H. (1980) Carbamazepine vs. Diphenylhydantoin vs. Their Combination in Adult Epilepsy. Neurology, 30, 354.

[22] Stringer, J.L. and Hinggins, M.G. (1994) Interaction of Phenobarbital and Phenytoin in an Experimental Model of Seizures in Rats. Epilepsia, 35, 216-220. http://dx.doi.org/10.1111/j.1528-1157.1994.tb02936.x

[23] Smith, D.B., Mattson, R.H., Cramer, J.A., Collins, J.F., Novelly, R.A. and Craft, B. (1987) Results of a Nationwide Veterans Administration Co-Operative Study Comparing the Efficacy and Toxicity of Carbamazepine, Phenobarbital, Phenytoin \& Primidone. Epilepsia, 28, 550-558. http://dx.doi.org/10.1111/j.1528-1157.1987.tb05778.x

[24] Kanner, A.M. and Frey, M. (2000) Adding Valproate to Lamotrigine: A Study of Their Pharmacokinetic Interaction. Neurology, 55, 588-591. http://dx.doi.org/10.1212/WNL.55.4.588

[25] Ghaffapour, M., Hejazie, S.S., Harirchian, M.H. and Pourmahmoodian, H. (2005) Phenytoin, Carbamazepine, Sodium Valproate and Lamotrigine Induced Cutaneous Reactions. Acta Medica Iranica, 43, 37-42.

[26] Mirelesh, R. and Leppik, E. (2007) Valproate and Clonazepam Comedication in Patients with Intractable Epilepsy. Epilepsia, 26, 122-126. http://dx.doi.org/10.1111/j.1528-1157.1985.tb05394.x

[27] Nicolson, A., Appleton, R.E., Chadwick, D.W. and Smith, D.F. (2004) The Relationship between Treatment with Valproate, Lamotrigine, and Topiramate and the Prognosis of the Idiopathic Generalised Epilepsies. Journal of Neurology, Neurosurgery \& Psychiatry, 75, 75-79.

[28] Arif, H., Nahm, E.A., Resor Jr., S.R. and Hirsch, L.J. (2008) Efficacy of Clobazam as Add-On Therapy for Refractory Epilepsy: Experience at a US Epilepsy Center. Clinical Neuropharmacology, 31, 333-338. http://dx.doi.org/10.1097/WNF.0b013e31815cd960

[29] Blaise, F.D. (1986) Bourgeois. Antiepileptic Drug Combinations and Experimental Background: The Case of Phenobarbital and Phenytoin. Archives of Pharmacology, 333, 406-411. http://dx.doi.org/10.1007/BF00500017

[30] Karas, C.A. (1986) Effects of Phenobarbital in Combination with Phenytoin or Valproic Acid on the Delayed-Matching-to-Sample Performance of Pigeons. Pharmacology Biochemistry and Behavior, 25, 929-932. http://dx.doi.org/10.1016/0091-3057(86)90409-0

[31] Kostadinova, I., Millusheva, M., Krustev, A. and Toreva, D. (1992) Effects of Phenobarbital, Carbamazepine and a Combination of Both on Corazol-Induced Changes in the Bioelectric Activity of Rat Brains. Folia Medica, 34, 20-23.

[32] Thomson, A.H. and Brodie, M.J. (1992) Pharmacokinetic Optimization of Anticonvulsant Therapy. Clinical Pharmacokinetics, 23, 216-230. http://dx.doi.org/10.2165/00003088-199223030-00004

[33] Bourgeois, B.F. (1988) Anticonvulsant Potency and Neurotoxicity of Valproate Alone and in Combination with Carbamazepine or Phenobarbital. Clinical Neuropharmacology, 11, 348-359. http://dx.doi.org/10.1097/00002826-198808000-00003

[34] Cereghino, J.J., Brock, J.T., Van Meter, J.C., Penry, J.K., Smith, L.D. and White, B.G. (1975) The Efficacy of Carbamazepine Combinations in Epilepsy. Clinical Pharmacology \& Therapeutics, 18, 733-741.

[35] Morris, J.C., Dodson, W.E., Hatlelid, J.M. and Ferrendelli, J.A. (1987) Phenytoin and Carbamazepine, Alone and in Combination Anticonvulsant and Neurotoxic Effects. Neurology, 37, 1111. http://dx.doi.org/10.1212/WNL.37.7.1111 